\title{
Editorial
}

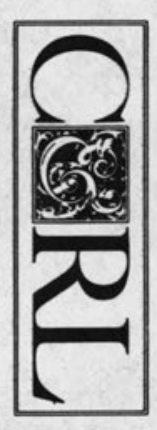

\section{Resource Sharing}

A series on the crisis of rising journal prices begins in this issue with an article by Kenneth Marks et al. Articles in subsequent issues will further define the problem and offer some directions toward resolution. A greater commitment to resource sharing must be one response to this conundrum.

The number of monographs, serials, and other formats appropriate to a college or university library has increased while the prices, particularly for serials, have exploded. At the same time, the introduction of online and CD-ROM technologies has made users more demanding. The laborious process of copying citations from a paper index might have slowed undergraduates' quest for knowledge in the past, but now they arrive at service desks with printed citation lists of esoteric books and journals. Further, the graduate student and the faculty researcher may produce an even more comprehensive and demanding list from specialized online databases. Only in the largest libraries can all of these citations be found locally. Thus, resource sharing is increasingly important as a strategy to meet users' needs.

David Weber's "A Century of Cooperative Programs among Academic Libraries" in the May 1976 issue of CERL chronicles and analyzes resource sharing programs. Historically, librarians speak eloquently about the need for sharing materials yet continue to build, to the best of their abilities, insular collections. The rhetoric of resource sharing heightens in proportion to increases in materials prices, declining values of the dollar, and erosions in local funding. But when these pressures on the materials budget ease, interest in resource sharing wanes. A modest interlibrary loan traffic can then meet the requests of dissertation writers and other serious scholars. However, in the last few years demand has increased dramatically, with interlibrary loan reflecting the expanded activity. For instance, among colleges in Oregon's State System of Higher Education, the increase has been 164 percent in just the last four years.

While technology in the form of electronic databases has increased demand, other technologies-grand bibliographic utilities and modest fax machines-have increased efficiencies. Sources of materials can be quickly identified; items can be ordered and delivered electronically. Nevertheless, technologies have generally outstripped policies and political commitments. Three areas require additional consideration to fulfill the technological potentials for resource sharing: policy development, funding, and cooperative collection development.

\section{POLICY DEVELOPMENT}

Although technologies and courier services have changed tracking and movement of materials, many individual institutions have not reexamined rules governing use of materials. While the local users' requirements should take precedence, the needs of other users in the region and around the country should also be considered. Users' needs are like widening concentric circles; the nearest deserves and receives greatest attention, but the others should not be 
ignored. For instance, lightly used serials might circulate between two campuses instead of being confined to one. Definitions of primary use should be rewritten to facilitate lending and borrowing. The "fair use" copyright rule should be examined for legal and practical standing. Five circulations within five years has been the standard practiceperhaps that logic should be tested.

Many large libraries fear that active participation in resource sharing will result in a reapportionment of access from the "haves" to the "have nots," from an inner concentric circle to an outer one. In some settings, this concern may be a legitimate one, worthy of serious consideration and study. However, the largest collections must expend resources to maintain their status. For instance, selecting and purchasing materials for a level-three collection is a fairly straightforward task, but seeking out and buying the materials that differentiate a level-five collection from a level four is an expensive task. Doing original cataloging for the distinctive level-five materials, much of them in foreign languages, costs a great deal more, too. In the same way, perhaps larger libraries will have to lend more to be able to borrow those items necessary to meet the more esoteric needs of their most specialized users.

\section{FUNDING}

The eloquent language surrounding resource sharing should find its corol- lary in eloquent funding. Failing to register local ownership on a national bibliographic database in order to save money is not an acceptable strategy. The networks have generally committed themselves to low fees for holdings registration. Only a small percentage of the institution's budget is required to continue to support participation in a bibliographic utility. Adequate staff must be provided to give timely interlibrary loan service. Other operations, such as cataloging, marking, and shelving, need to provide effective support.

\section{COOPERATIVE COLLECTION DEVELOPMENT}

Especially in resource-poor areas, cooperative collection development must become a reality. While collection conspectuses and shelf list counts have done much to identify areas of strength, this information seems to have had only a modest effect on establishing parameters for cooperation. As the definitions of different collective levels become more precise, their impact on actual practice should increase. Few states or regions can afford to support overlapping levelfive collections in any area.

The tradition of resource sharing is proud but unrealized. New technologies make resource sharing one of the most challenging areas of librarianship. Policy, funding, and cooperative collection development must now rise to meet the level of technological promise.

GLORIANA ST. CLAIR

\section{IN FORTHCOMING ISSUES OF \\ COLLEGE \& RESEARCH LIBRARIES}

Resolving the Acquisitions Dilemma: Into the Electronic Information Environment by Eldred Smith

ARL Directors: Two Decades of Changes

by Marcia J. Myers and Paula T. Kaufman

The Bottomless Pit Revisited

by Larry Hardesty

Subject Cataloging of Personality Tests

by Robert P. Jordan

Research Notes

Literature of Academic Libraries by John M. Budd 